\title{
Student Reflections on Urban Physical Education and Involvement in College Physical Activity
}

\author{
Jeremy Lackman ${ }^{1} \&$ Jepkorir "Rose" Chepyator-Thomson ${ }^{2}$ \\ ${ }^{1}$ Health and Physical Education, Monmouth University, USA \\ ${ }^{2}$ University of Georgia, USA \\ Correspondence: Jeremy Lackman, Assistant Professor of Health and Physical Education, Monmouth University, \\ USA.
}

Received: November 19, 2018

Accepted: January 4, 2019

Online Published: March 31, 2019

doi:10.5430/irhe.v4n2p1

URL: https://doi.org/10.5430/irhe.v4n2p1

\begin{abstract}
The purpose of this study was to understand freshman college students' reflections on urban high school physical education (PE) programs and to discern the extent to which their experiences influenced college physical activity. Sixteen university freshman students enrolled in a college PE class who had taken at least one high school PE class in an urban school setting were interviewed. Data collection methods included open-ended semi-structured qualitative interviews. Using constant comparative analysis, the reflective findings of the study revealed that students who had positive experiences had increased college physical activity involvement.
\end{abstract}

Keywords: physical activity, college/university, urban physical education, student reflections

Research studies link the effects of physical activity to positive physiological and psychological health outcomes (Kilpatrick, Hebert, \& Bartholomew, 2005), with regular physical activity being linked to reduced risk of chronic diseases such as cardiovascular disease (Conroy, Cook, Manson, Buring, \& Lee, 2005). The largest drop off rate of regular physical activity occurs between high school and college (Njororai and Njororai, 2015), and college students often experience challenges that minimize their involvement in physical activity, leading to a major decline in physical activity (Barney, Pleban, Wilkinson, \& Prusak, 2015; Curry, Jenkins, \& Weatherford, 2015; Hardin, Andrew, Gi-Yong, \& Bemiller, 2009; Grace, 1997). The purpose of this study was to understand freshman college students' reflections on urban high school physical education (PE) programs and to discern the extent to which their involvement in those urban PE programs had on their college physical activity participation and enrollment in college PE classes.

\section{Theoretical Perspective}

Social cognitive theory (Bandura, 1986, 1989) guided this research investigation. This theory helps explain individuals' involvement in physical activity. Understanding individual thoughts about joyful experiences and engagement in physical activity in high school or community environments would inform curriculum development and implementation and would underscore the importance of understanding experiences of students' reflection of high school PE programs and extent of involvement in college PE programs. In context of social cognitive theory, individual's involvement in physical activity rests on interactive experiences connected to one's behavior, environment, and personal factors (Lodewyk \& Pybus, 2013; Bandura, 1989) shaped by involvement in physical activities within schools. Scholars argue that school-based programs enhance youth development particularly in under-resourced communities because of the availability of structured activities and supervision in safe environments (Holt, Sehn, Spence, Newton, \& Ball, 2012). This is congruent with the view that school-based PE is beneficial to all students because it lays a foundation for lifelong involvement in physical activity, hence leading to healthy lifestyles as adults (Gordon-Larsen, McMurray, \& Popkin, 2000). It is considered that participation in physical activity during high school PE would likely increase the possibility that students will continue physical activity after high school.

\section{Review of Related Literature}

Regular physical activity through school PE programs can play an important role in helping reduce childhood obesity. The idea of school based curricular interventions is not a recent occurrence and increasing physical activity has been used to try to combat obesity (Xu, Chepyator-Thomson, \& Culp, 2010). Physical education curricular interventions are a key components, as they provide a foundation for the promotion of lifelong activity and promote healthy 
lifestyle choices (Xu et al., 2010). In fact, "PE classes may be the only opportunity for many adolescents to engage in weekly physical activity" (Gordon-Larsen et al., 2000, p. 88). However, physical activity involvement decreases in adolescence, with the risk being greater for urban, economically disadvantaged, and minority youth (Dyson, Coviello, DiCesare, \& Dyson, 2009). Children from resource-limited communities or who come from racial or ethnic minority backgrounds tend to be faced with problems of being overweight or obese (Gordon-Larsen et al., 2000), particularly those residing in urban environments, where schools have limited educational and recreational resources. In fact, children in some economically disadvantaged families may face higher risks of being overweight, (Ogden, Carroll, Curtin, Lamb, \& Flegal, 2010) particularly in urban environments. In addition, urban adolescents reported lower engagement in physical activity than suburban and rural adolescents (Springer, Hoelscher, \& Kelder, 2006).

\subsection{High School PE Experiences and College Physical Activity Participation}

Mears (2010) reported that student participation in high school PE influences levels of physical activity involvement among young adults. Positive exposure to high school PE programs impacts students' involvement later in college at the moderate and vigorous levels (Dale \& Corbin, 2000). Recent research has focused on physical activity levels of college students in physical activity programs (Barney et al., 2015; Curry et al., 2015; Hardin et al., 2009) but there are limited research studies that link high school PE experiences with college PE or activity.

Chepyator-Thomson, Russell, \& Culp (2007) studied African American women in college PE activity programs, focusing on their reflections on their K-12 PE. The study found that participation in PE declines steadily from elementary to the high school years, with participation being almost non-existent in high school and college. This was often due to negative experiences encountered during PE in middle and high school. Hildebrand and Johnson's (2001) research study found that students' experiences in quality PE programs in high school resulted in higher levels of PE class enrollment in university. Quality high school PE experiences can be influential in reducing the physical inactivity trends of college adults (Hildebrand \& Johnson, 2001).

As can been seen from previous research, experiences in high school PE (both positive and negative) can later impact a person's life, choices of participation, physical activity level, future participation in PE, and even their health. It is imperative that PE, in all settings, but especially in urban settings, be a quality program whereby students learn and grow in a safe and nurturing environment and learn how to be healthy adults.

\subsection{High School PE Experiences and College Physical Activity Class Choice}

Just as enjoyment is the primary intrinsic reason that students give for participating in physical activity in college (Blankenship, 2008), the majority of students enroll in college PE courses for enjoyment (Lackman, McNeill, \& Smith, 2015; Hildebrand \& Johnson, 2001). For example, Hildebrand and Johnson's (2001) study showed the majority of students enrolled in their college PE activity classes because they enjoyed the activity and had interest in the activity. Other research states that fun was the dominant reason for enrolling and participating in PE activity classes among college students (Ciucci, 2010; Weinfeldt \& Visek, 2009). Some other research has found that students enroll in PE courses in college to exercise or to stay healthy (Lackman et al., 2015; Weinfeldt \& Visek, 2009).

In summary, college students participated in physical activity in college for purposes of weight management, social interaction, and enjoyment and enrolled in college PE classes for purposes of having fun, exercising regularly, and improving their fitness levels. High school PE experiences influenced involvement in college physical activity showing that students who enrolled in more PE in high school were more physically fit in college. High school PE experiences have also influenced college PE, showing that students who disliked PE in high school were more likely to not participate in PE in college. No studies to date have been conducted on students' experiences in urban high school PE to understand how these experiences influence later college PE and activity choices. The purpose of this study was to understand freshman college students' reflections on urban high school PE programs and to discern the extent to which their experiences influenced selection of college physical activity participation and enrolment in college PE classes. The research questions that guided this study centered on the following: 1) How does out of school physical activity in an urban school setting influence physical activity involvement in college and 2) How do college students make decisions in regards to physical activity and PE class choice based on their urban high school PE experience?

\section{Method}

\subsection{Research Context}

A southeastern university was chosen primarily because of its uniqueness: the university requires all students to take and pass a one credit hour of PE activity course to graduate and secondarily because it was convenient to the researchers. Freshman students were chosen because of their proximity to having completed high school PE. The 
researchers distributed a survey to all students in PE activity classes during a fall term. This was done to determine which students were freshman and which students came from an urban high school setting. Once the surveys were complete, the researchers invited the students who were freshman in their first semester of school at the university who also had taken at least one high school PE course in an urban setting to participate in the study. Students who met the criteria volunteered to be a part of the study and volunteered to be interviewed. All participants were between 18-25 years old and included males and females. A summary of interviewee demographics is provided in Table 1. All participants were kept confidential and were given pseudonyms.

Table 1. Summary of interviewees

\begin{tabular}{lllll}
\hline Pseudonym & Gender & Race & PE class in College & $\begin{array}{l}\text { Sport or Fitness } \\
\text { College PE }\end{array}$ \\
\hline Callie & Female & Caucasian & Beg Volleyball & Sport \\
\hline Chris & Female & Caucasian & Beg Volleyball & Sport \\
\hline Sylvia & Female & Caucasian & Beg Volleyball & Sport \\
\hline Juliet & Female & Caucasian & Beg Volleyball & Sport \\
\hline Emily & Female & Caucasian & Beg Volleyball & Sport \\
\hline Zane & Male & Caucasian & Beg Tennis & Sport \\
\hline Sally & Female & Hispanic & Beg Tennis & Sport \\
\hline Sandy & Female & Caucasian & Intermediate Tennis & Sport \\
\hline Jamie & Male & Caucasian & Beg Racquetball & Sport \\
\hline Amber & Female & Hispanic & Beg Racquetball & Sport \\
\hline John & Male & Caucasian & Basketball & Sport \\
\hline Stacy & Female & African- & Badminton & Sport \\
& & American & & \\
\hline Diamond & Female & Asian & FFL Jogging & Fitness \\
\hline Hannah & Female & Caucasian & FFL Jogging & Fitness \\
\hline Dale & Female & Caucasian & FFL Swimming & Fitness \\
\hline Johann & Male & Caucasian & Weight Training & Fitness \\
\hline
\end{tabular}

\subsection{Research Design and Participants}

A qualitative research design was used in this study. As Creswell (2009) explains, using qualitative research allows the "researcher to establish meanings of a phenomenon from view of participants" (p. 16), allowing participants to show how "their social experiences are given meaning" (Denzin \& Lincoln, 2005, p. 10). The researchers used open ended, qualitative interviews. Participants were 16 undergraduate freshman students at a southeastern, four-year, public university that were enrolled in different PE activity classes who had taken at least one PE class in an urban high school setting. Participants were interviewed for approximately 30 to 45 minutes and questions used in the interview centered on urban high school PE experiences and involvement in college physical activity and PE courses.

\subsection{Data Collection and Data Analysis}

Data collection involved open-ended, semi-structured interviews as this allowed the researchers to gain insight into students' experiences in urban high school PE programs. Constant comparison method was used to analyze the data as it allowed the researchers to analyze for themes that emerged from the interview transcriptions (Saldana, 2016). The data were coded and then organized into categories and finally into themes by two separate researchers to prevent bias and strengthen validity. The researchers then met and agreed on common themes. Using this methodological framework, the researchers were able to give voice to the participants and understand their experiences in urban high school PE and to determine how those experiences influenced their college physical activity and PE choices and involvement. 


\section{Results}

This study involved college students enrolled in a PE class during their first semester of their first year who attended urban high schools. The results focus on student experiences in urban PE and the choice of physical activities and PE classes in college. Themes emerging from this study describe the impact urban high school and urban high school PE had on college physical activity involvement and on selection of college PE courses.

\subsection{Involvement in Urban High School PE and College Physical Activity}

Physical activity outside of the urban high school PE class had a greater influence on continued physical activity involvement in college than a positive or negative involvement in an urban PE class. Eighty-eight percept of the participants were active in physical activity outside of urban high school PE and the same individuals had both positive and negative experiences in urban high school PE, yet all of them continued participation in physical activity in college. Examples of participants who continued to be involved in physical activity in college but had differing experiences in PE in urban high schools are described below.

Amber. Amber enjoyed playing sports and being active. She played tennis for the high school team and was a junior ranked tennis player outside of school sports. She practiced every day and also participated in games and tournaments on the weekends. She worked out and went to the gym three days a week, doing running, the treadmill, and weight exercises. She also walked her dog, and on vacation, she would go on hikes with her family. In regard to her PE class, Amber had negative experiences. Her teacher "did not care", "we didn't learn anything", and "he was like a paid babysitter". When asked to evaluate her high school program, Amber said:

I don't think it was very good, especially now in college, where I'm in a really good class for a specific sport and stuff. It was just a graduation requirement. It was just something to do. No one took it seriously, and I don't think anyone necessarily looked forward to it.

When asked about the influence her high school PE program had on her, Amber stated "I like sports in general, so it was always fun for me to play...I don't think any of the students or the teachers made an impact on that. It's just kind of fun to get out there and play". Apparently, the PE teachers and program did not influence Amber's outlook on physical activity. Amber continued her involvement in physical activity in college; she plays tennis on the weekends with friends, joined the club tennis team, walks to all of her classes, and ran a $5 \mathrm{~K}$ in addition to working out three days a week. Amber also participated in college physical activities that were similar to what she did in high school. She stated: "I go to the gym every week, same as I did before I came to college".

Chris. Chris enjoyed playing sports and being active. She played volleyball for her school and for a club team, which entailed practice every day and also games and tournaments on the weekends. She would walk her dogs, bike and run on the beach, and walk the neighborhood with her mom. In regard to her PE class, Chris had positive experiences. She liked her teacher stating, "She was really cool". Her classes were structured, and she received constant feedback from her teacher. When asked to evaluate her high school program, Chris said "I would evaluate it, during my time, as very good...like I remembered wanting to go and having fun". Chris continued her physical activity from high school into college and walks to all of her classes, and three to four days a week, she runs two miles. She also stated that: "I do more kind of like a circuit, the elliptical for 10 minutes, some squats, weights and everything. I try to do that at least three days of the week". While Chris was not on an intramural team at the time of the interview, but she did state that she wanted to join an intramural team next year. Chris also continued some of the exact same physical activities she did in high school while in college, she said: "When I go home, walks on the beach, couple of miles, ride the bikes, general things". The study revealed that for students who were already active in high school, having a positive or negative PE experience might not necessarily impact physical activity involvement in college. What happened in both situations above is that students did not stop being physically active in college, regardless of whether the students had positive or negative experiences in high school PE.

\subsection{High School Physical Education and Physical Activity Experiences}

Some of the participants had limited physical activity involvement in high school with positive experiences in high school physical education. These participants tended to be more physical active in college. Examples are provided below.

Stacy. Stacy was not involved in physical activity outside of PE in high school at all. When asked about sports outside of PE she did not play any. When asked about her physical activity outside of PE in high school she said she did "very little". When asked about her doing activities like walking, jogging or organized workouts, she replied "sometimes...if I had time on the weekends, I would do so with my parents". 
In regard to her high school PE class, Stacy had positive experiences. When asked what she thought of her PE program while in high school, Stacy said: "It was, yeah, a good experience, definitely". She liked her class and her teacher and "enjoyed PE", she stated:

Well the high points would definitely be how fun it was, and we were all required to participate and that made it more enjoyable because of our coach. The low points would be -- well it wasn't always so fun, especially when the tests came around. There was really no low point -- there was nothing that really stood out as boring because in a way it all became fun.

When asked about her physical activity outside of her college PE class, Stacy became more involved in physical activity in college. In college, she started "walking with my friends a lot". She walks seven days a week and walks to and from her classes. She expressed that:

Well, we're kind of focusing too much on school, we put too much stress on ourselves, so we decided that instead of watching TV let's just -- it's just so much better to walk, I don't know it's just so much better. So we just came up -- we didn't exactly say let's walk, it just happened in a way, it's become a schedule for us now.

Stacy plans on continuing to walk in later semesters. Stacy also was considering joining intramurals and even club sports in college. Stacy was asked about the impact her high school PE class had on her and she said: "I guess the fact that it made me more physically active because I wasn't that active before PE".

The participants who had limited or negative physical activity involvement in high school were similarly not involved in college physical education courses. Examples are provided below.

Diamond. Diamond was not involved in physical activity outside of high school PE. When asked about sports outside of PE she did not play any. When asked about her physical activity outside of PE in high school she said she did "some dance". She participated in cultural programs at her temple. She would "dance and show the little kids in the family some of them". When asked about the frequency of dancing, she said about one in the fall and two in the spring, or three times a year. When asked about her doing activities like walking, jogging or organized workouts, she replied that she did not do any.

In regard to her PE class, Diamond had negative experiences. She stated that: "I'm not really athletic" and that high school was focused on fitness and "it was really tough for me because I couldn't do it". When asked about fitness, she said she had a hard time with the running, and the crunches and sit-ups. It was simply not enjoyable for her. When asked about her high school PE, Diamond said:

Yeah. I never hated it. I never complained. I just kind of accepted it as part of my class. I, personally, don't enjoy stuff like that. I should, so I could get healthier, but I don't. I don't know if I would say it's fun, but I wouldn't have a problem with it.

Diamond was asked if she enjoyed her high school program, and she said: "Not really. Not in the actual class. I wouldn't say I loved it, but I like umm, just did it. I accepted that it was part of my class and I did it".

When asked about physical activity in college outside of her college PE class, Diamond said she wasn't involved in any but was going to join a dance team. She was still involved with dance at her temple and had to attend a total of five practices. She also helped teach younger kids to dance, like she did in high school. In this case, a bad experience in high school PE did not decrease or increase the amount of physical activity from high school to college; it stayed about the same but was very limited. In this study, a negative urban high school PE experience does not necessarily change a person's physical activity level in college, which corroborates a previous finding by Chepyator-Thomson et al. (2007). However, as was seen in Stacy's case previously, a low level of physical activity in high school can be changed and increased in college with a positive high school PE experience.

\subsection{Reasons for Student Enrollment in College Physical Activity Classes}

Students enrolled in PE classes for a variety of reasons. At the southeastern university, all students, at some time in their college career have to take and pass a one credit hour PE activity course. There were plenty of PE courses for students to select, and each student selected a class for their own reasons: fulfilled credit requirement, maintained or improved performance, chosen based on prior experience with high school sport, or to learn a new sport.

Fulfill credit requirement. Students selected the PE course to meet credit requirements during their first semester. Many freshmen took PE courses to meet the number of hours needed to receive financial aid, to meet honors requirements, or for full-time status. Often, when students needed a one credit hour class to fill their schedule, they chose PE. Because students at the southeastern university had to take and pass a PE in order to graduate at some time 
in their college career, many freshmen said they wanted to get the requirement out of the way, so they could focus on their major classes. Chris and Amber said they wanted to take PE to "get it out of the way". Emily said: "Honestly, I was at 11 hours and I didn't want to take another like three-hour class so I just chose the PE". Johann was at 14 hours and had time, so he enrolled in PE. Chris stated, "I wanted 15 credits instead of 14, to have a technically full schedule". Amber, Sylvia, Zane, Sally, and John needed one more credit for honors purposes with Amber stating: "I wanted exactly 15 hours, and then the hour that you get with PE, it would go exactly to 15 hours".

Maintain or improve performance. Some students took the class because they wanted to improve their health, get or stay in shape, lose weight, or get better in their participation in their PE course. Diamond said:

One of like my goals when I came to high school was to lose weight because I gained a lot of weight this summer. I thought if I started jogging in like a class environment, maybe, I would get motivated enough and I would build my endurance up enough to do it outside of class.

Hannah was going to a military academy after her freshman year, and needed to be in shape, so she chose a jogging class to motivate her to run every day. Johann decided he wanted to get physical activity so he enrolled in weight training, he said "it makes me get up and do something" and Dale took swimming because "I thought it would benefit me, in more a physical activity way, like I get more physical activity out of it than I would throwing a bowling ball or just walking...so that's why I chose it". Students also enrolled in specific courses in PE to get better at the sport or skill. Callie wanted to get better at volleyball because "We have a volleyball court outside my dorm, so it would be cool to get better at it, so I can play and not be the worst on spring break".

Prior experience with high school sport. Often students took a PE class because it was familiar to them; they had either played the sport in high school or they had experienced the sport during high school PE. Diamond did a lot of fitness-based running in her high school PE class, and in college she enrolled in a jogging class. When asked if she chose jogging because of her previous high school experiences, she said "maybe subconsciously. I don't know, maybe".

Many students signed up for PE classes that were sports they had done in high school. For example, John played basketball during high school and signed up for basketball in college, and Chris and Emily played volleyball in high school and took volleyball in college. Johann took weight training in college because "I did weight training in high school and on my own" and Zane and Sandy played tennis in high school, and continued to take tennis courses in college. Callie took volleyball in college because she had played "recreationally," and Sylvia stated she enrolled in volleyball because she had experience playing the sport before. She explained that:

I saw that basketball fit and I liked playing basketball but then I kept checking frequently to see if other ones were open in other classes. And then I used to play tennis when I was younger too, so I thought oh tennis might be fun, and I was thinking that basketball might be kind of intense but then I think I changed one of my classes around which then eventually opened up a spot for the volleyball class.

"I wanted to try something new". Some students charted unfamiliar territory; they wanted to learn a new sport or skill. For example, Stacy stated: “well honestly I didn't want to do walking because I do that every day and I wanted to try something new because volleyball would kind of be the same thing I've done before, badminton is something I've never really done". Another example is Amber, who "wanted to learn a new sport". She explained:

I picked a sport...that I had never tried before, and I thought that ...Well, I'd played racquetball a few times with my dad before, but never like seriously, so I thought that would be something fun to do...Like racquetball is just such a different, cool sport. It's not ever offered, so I thought it would be cool to try it out.

Sylvia never got to play volleyball in high school, due to cross-country, so she was excited to take a volleyball class. This was because she hadn't had a chance to experience playing volleyball before, so she enrolled in volleyball in college. Another example of a student trying something new was Jamie, who took racquetball in college and said:

Racquetball has always seemed interesting to me because whenever I've visited colleges they're always like we have racquetball courts, look at them. And I saw people playing and I was kind of like I don't understand what they're doing and it looks terrifying and fun so when I saw it was an option I signed up for it.

As can be seen from the previous examples, students chose their reasons for enrolling in their required PE activity course in college for a wide variety of reasons, but prior experience (or lack thereof) in high school PE, was a major factor, supporting previous research by Lackman et al., (2015), Ciucci (2010), Weinfeldt and Visek (2009), Blankenship (2008), and Hildebrand \& Johnson (2001). This also provides further support for the concept of a 
quality urban high school PE program, because if students enjoy doing high school PE, or are exposed to new fun concepts, they are likely to enroll in and enjoy college PE as well, thereby promoting a healthy lifestyle.

\section{Discussion}

This research study revealed that students' positive high school PE experiences helped them to continue to be involved in physical activity in college; hence having a positive PE experience in the secondary years could play a pivotal role in students' engagement in physical activity outside of PE and later in life. This corroborates previous research by Hildebrand and Johnson (2001) that found enjoyment in PE in high school could positively influence physical activity and PE participation in college.

Understanding students' perspectives on their learning and involvement in urban PE programs could indicate ways to improve education that students receive in college, necessitating the focus on student voice research. This study showed freshman students enrolled in college PE to meet the graduation requirement and because it fit their schedules. These findings are similar to previous research (Blankenship, 2008; Ciucci, 2010; Hildebrand \& Johnson, 2001; Weinfeldt \& Visek, 2009). Many freshman students took an additional course in PE beyond their graduation requirement, depending on scheduling, course load for their major, and interest in the course or fun, corroborating previous studies' findings (Mears, 2010; Weinfeldt \& Visek, 2009). However, despite previous research stating that students in high school and between high school and college are inactive (Dyson et al., 2009), in this study, most participants stated they were fairly active outside of their urban high school PE program and were involved in structured and unstructured activities and sports, including school sports, community sports, club sports, pick-up games, outdoor activities, and working out. The difference in findings may be explained by the fact that in this study, the students self-labeled themselves as fairly active: there were no objective measures used to compare their physical activity involvement to other students or to their past activity.

According to the social cognitive theory, if students do not develop sport skills in school or feel successful using them, they would not feel as competent to perform sports activities (Trost, Pate, Dowda, Saunders, Ward, \& Felton, 1996). In this study, it was found that previous physical activity involvement seemed to have a stronger relation to continued involvement in physical activity as compared to participation in PE courses. For instance, the individuals who were fairly active in high school outside of PE and who either had positive or negative experiences in PE still continued their physical activity involvement in college. Individuals who had limited involvement in physical activity outside of high school but who enjoyed PE in high school actually increased their physical activity involvement in college. This shows that a positive PE experience in high school can have positive effects on physical activity participation in college, while a negative high school PE experience may not necessarily result in a change in physical activity in college. However, it can be said that a quality urban high school PE program can affect change, so the idea is to improve urban PE programs to enhance physical activity participation outside of school and later in life.

In Prusak, Davis, Pennington, and Wilkinson's (2014) study, elementary students felt their PE experience had an effect on their current out-of-class behaviors, indicating they enjoyed doing the activities they learned in class during recess or after school. Student involvement in urban high school PE influenced their choices of physical activity in college; many participants chose a PE class in college because they had experience with it in high school or they wanted to try something new. Promoting confidence through student enjoyment of physical activity and PE programs could be considered a major goal in teacher education. As documented in this study, students enrolled in college PE classes if they enjoyed and had positive experiences in their high school PE. Therefore, it is important for PE programs in college and high school to provide quality instructional programs that meet the needs of all students. Physical education programs can be improved to be more student centered, be more engaging, focus more on non-traditional activities instead of traditional sports, and appeal to modern students in urban environments from diverse cultures and backgrounds. A concluding point from this study is that physical education plays a pivotal role in students' lives in high school and later in life in improving the level of physical activity involvement.

\section{Limitations of the Study}

Limitations of the study include the fact that only students enrolled in a PE course as a college freshman were interviewed and the study focused on one southeastern university, and only during one term. In addition, the participants were chosen from a pool of students enrolled in PE courses who had to take at least one PE activity class in college to graduate, and who volunteered to be a part of the study. The majority of the participants were females. This means that this study may not be representative of all freshman, university students, or urban students. Further studies should continue to study student voice specifically in urban high schools to understand this different and growing demographic. 


\section{References}

Bandura, A. (1986). Social foundations of thought and action: A social cognitive theory. Englewood Cliffs, NJ: Prentice-Hall.

Bandura, A. (1989). Human agency in social cognitive theory. American Psychologist, 44(9), 1175-1184. https://doi.org/10.1037/0003-066X.44.9.1175

Barney, D., Pleban, F. T., Wilkinson, C., \& Prusak, K. A. (2015). Identifying high school physical education physical activity patterns after high school. Physical Educator, 72(2), 278-293.

Blankenship, B. T. (2008). The Psychology of Teaching Physical Education: From Theory to Practice. Scottsdale, AZ: Holcomb Hathaway.

Chepyator-Thomson, J. R., Russell, J. A., \& Culp, B.O. (2007). African American college women's reflections on physical activity involvement during public school years. Journal of African American Studies, (11)2, 101-117. https://doi.org/10.1007/s12111-007-9012-7

Ciucci, S. (2010). Student participant motivation to enroll and participate in activity courses at Gonzaga University. Ann Arbor, MI: ProQuest LLC.

Conroy, M. B., Cook, N. R., Manson, J. E., Buring J. E., \& Lee, I. (2005). Past physical activity, current physical activity, and risk of coronary heart disease. Medicine \& Science in Sports \& Exercise, 1251-1256. https://doi.org/10.1249/01.mss.0000174882.60971.7f

Creswell, J. W. (2009). Research design: Qualitative, quantitative, and mixed methods approaches (3rd ed.). Thousand Oaks, CA: Sage.

Curry, J., Jenkins, J. M., \& Weatherford, J. (2015). Focus on freshman: Basic instruction programs enhancing physical activity. Physical Educator, 72(4), 621-640. https://doi.org/10.18666/TPE-2015-V72-I4-6472

Dale, D., \& Corbin, C. B. (2000). Physical activity participation of high school graduates following exposure to conceptual or traditional physical education. Research Quarterly for Exercise and Sport, 71, 61-68. https://doi.org/10.1080/02701367.2000.10608881

Denzin, N. K., \& Lincoln, Y. S., (2005). The sage handbook of qualitative research (3rd ed.). New York, NY: Routledge.

Dyson, B., Coviello, N., DiCesare, E., \& Dyson, L. (2009). Students' perspectives of urban middle school physical education programs. Middle Grades Research Journal, 4(4), 31-52.

Gordon-Larsen, P., McMurray, R. G., \& Popkin, B. M. (2000). Determinants of adolescent physical activity and inactivity patterns. Pediatrics, 105, e83. https://doi.org/10.1542/peds.105.6.e83

Grace, T. W. (1997). Health problems of college students. Journal of American College Health, 45, $243-250$. https://doi.org/10.1080/07448481.1997.9936894

Hardin, R., Andrew, D. P. S., Gi-Yong, K., \& Bemiller, J. (2009). Motivational factors for participating in basic instruction programs. Physical Educator, 66(2), 71-84.

Hildebrand, K. M., \& Johnson, D. J. (2001). Determinants of college physical activity class enrollment: Implications for high school physical education. The Physical Educator, 58(1), 51-56.

Holt, N. L., Sehn, Z. L., Spence, J. C., Newton, A. S., \& Ball, G. D. C. (2012). Physical Education and Sport Programs at an Inner-City School: Exploring Possibilities for Positive Youth Development. Physical Education and Sport Pedagogy, 17(1), 97-113. https://doi.org/10.1080/17408989.2010.548062

Kilpatrick, M., Hebert, E., \& Bartholomew, J. (2005). College students' motivation for physical activity: Differentiating men's and women's motives for sport participation and exercise. Journal of American College Health, 54(2), 87-94. https://doi.org/10.3200/JACH.54.2.87-94

Lackman, J., McNeill, E. B., \& Smith, M. L. (2015, June 24). Freshman college students' reasons for enrolling in and anticipated benefits from a basic college physical education activity class. Frontiers in Public Health Public Health Education and Promotion. https://doi.org/10.3389/fpubh.2015.00162

Lodewyk, K. R., \& Pybus, C. M. (2013). Investigating factors in the retention of students in high school physical education. Journal of Teaching in Physical Education, 32(1), 61-77. https://doi.org/10.1123/jtpe.32.1.61

Mears, M. (2010). Physical education waivers and young adult activity. The Physical Educator, 67(2), 90-100. 
Njororai, W. M., \& Njororai, F. (2015). College undergraduate students' self-rating of their physical activity involvement over a 7-day period. Journal of Physical Education \& Sport, 15(3), 502-508.

Ogden, C. L., Carroll, M. D., Curtin, L. R., Lamb, M. M., \& Flegal, K. M. (2010). Prevalence of high body mass index in US children and adolescents, 2007-2008. The Journal of American Medical Association, 303(3), 242-249. https://doi.org/10.1001/jama.2009.2012

Prusak, K. A., Davis, T., Pennington, T. R., \& Wilkinson, C. (2014). Children's perceptions of a district-wide physical education program. Journal of Teaching in Physical Education, 33, 4-27. https://doi.org/10.1123/jtpe.2013-0004

Saldaña, J. (2016). The coding manual for qualitative researchers (3rd ed.). Los Angeles, CA: SAGE.

Springer, A. E., Hoelscher, D. M., \& Kelder, S. H. (2006). Prevalence of physical activity and sedentary behaviors in US high school students by metropolitan status and geographic region. Journal of Physical Activity \& Health, 3(4), 365-380. https://doi.org/10.1123/jpah.3.4.365

Trost, S. G., Pate, R. R., Dowda, M., Saunders, R., Ward, D. S., \& Felton, G. (1996). Gender differences in physical activity and determinants of physical activity in fifth grade children. Journal of School Health, 66(4), 145-150. https://doi.org/10.1111/j.1746-1561.1996.tb08235.x

Weinfeldt, J. A., \& Visek, A. J. (2009). Why college students enroll in exercise and sport activity classes: An exploratory investigation. Missouri Health, Physical Education, Recreation and Dance, 19, 64-76.

Xu, F., Chepyator-Thomson, J. R., \& Culp, B. (2010). School-based physical education programs and obesity in the United States: Trends, rationalizations, and perspectives of change. Educational Research Journal, 25(2), 241-262. 